\title{
Predictive role of cytokine gene polymorphisms for the development of femoral head osteonecrosis
}

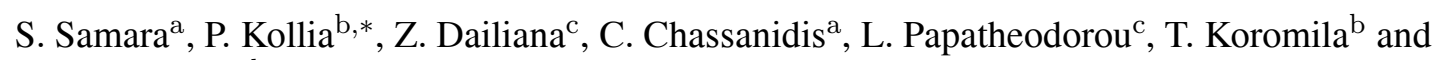 \\ K.N. Malizos ${ }^{\mathrm{c}, \mathrm{d}}$ \\ ${ }^{a}$ Laboratory of Medical Genetics and Cytogenetics, Faculty of Medicine, School of Health Sciences, University of \\ Thessalia, Larissa, Greece \\ ${ }^{\mathrm{b}}$ Laboratory of Human Genetics, Faculty of Biology, University of Athens, Athens, Greece \\ ${ }^{\mathrm{c}}$ Department of Orthopaedic Surgery, Faculty of Medicine, School of Health Sciences, University of Thessalia, \\ Larissa, Greece \\ ${ }^{\mathrm{d}}$ Center for Research and Technology-Thessalia (CERETETH), Institute of Biomedical Research and Technology, \\ Larissa, Greece
}

\begin{abstract}
Introduction: Osteonecrosis (ON) is a multifactorial disease that leads to hip destruction. Lately, much focus has been at femoral head preservation with nonsurgical methods. In this study we examined the polymorphisms of IL-1 $\alpha$, IL-1R, IL-1RA, IL-4R $\alpha$, IL-1 $\beta$, IL-12, $\gamma$ IFN, TGF- $\beta$, TNF-a, IL-2, IL-4, IL-6 and IL-10 genes for evaluation of their contribution in ON.

Material and methods: DNA was extracted from $112 \mathrm{ON}$ patients and 438 healthy donors. Analysis of the polymorphisms was completed using the PCR-SSP method. Statistical analysis was performed using the $\chi^{2}$ test to compare the genotype and allelic frequency distribution.

Results: The CT and GA genotypes of the IL-1 $\alpha(-889)$ and TNF-a (-238) genes were found higher in the patients $(51.8 \%$ and $10.8 \%$, respectively) compared to the healthy donors (39.7\% and $2.1 \%$, respectively). In TGF- $\beta$ codon 25 , the $\mathrm{G}$ to $\mathrm{C}$ polymorphism in the homozygous state was found in $1.8 \%$ of the patients and the $\mathrm{C}$ allele frequency was $8.9 \%$, whereas the $\mathrm{G}$ allele frequency was $91.1 \%$. Also, at the IL-10 (-1082) gene the GG genotype was $16.2 \%$ in the controls whereas in the patients was $7.2 \%$.

Conclusions: Based on the above, we showed that certain genotypes of the IL- $1 \alpha$, TGF- $\beta$, IL-10 and TNF-a genes could be related in the pathogenesis of a complicated disease, such as osteonecrosis. The presence of one of the above mentioned polymorphisms or the simultaneous carriage of more than one may further increase the risk for osteonecrosis, especially in those at high risk, such as patients receiving corticosteroids.
\end{abstract}

Keywords: Osteonecrosis, avascular necrosis, cytokines, interleukins, osteoblasts, osteoclasts

\section{Introduction}

Osteonecrosis $(\mathrm{ON})$ is a devastating disease usually leading to hip joint destruction in the third through fifth decades of life (average age, 36 years) [12,34, $35,40]$. The results of arthroplasty in these patients

\footnotetext{
*Corresponding author: Panagoula Kollia, Department of Biology, School of Physical Sciences, National and Kapodistrian University of Athens, Panepistimioupolis, 157 01, Athens, Greece. Tel.: +30 2107274 401; Fax: +30 2107274 318; E-mail: pankollia@ biol.uoa.gr.
}

were considered less than satisfactory, as failure rates up to $20 \%$ at a 5 year's follow up were initially reported [38]. However, recent studies with long term follow up (average of 17 years) report failure rates up to $17 \%$ [16]. ON is believed to be a multifactorial disease that is associated in some cases with both a genetic predilection as well as exposure to certain risk factors. These risk factors include corticosteroid use, alcohol intake, smoking and various chronic diseases (renal disease, hematological disease, inflammatory bowel disease, post-organ transplantation and hypertension) $[1,7,11,14,19,20,25,26,41]$. 
The pathology of osteonecrosis involves ischemic events followed by death of bone and marrow elements. A process of repair is then initiated, but unless the lesion is small (less than $15 \%$ of the femoral head involved), this repair process is usually ineffective. The net result is weakening of subchondral bone with subsequent collapse of the articular surface [27]. This can lead to eventual collapse of the architectural bony structure of the femoral head, leading to joint pain and loss of function [3]. The vascular supply to the femoral head is affected by many endogenous and exogenous factors, such as thrombophilia, hypercortisonism and alcoholism. Common belief is that all of these factors run through diverse pathways to focal thrombosis and eventual osteonecrosis [15].

Nowadays, much focus has been on modalities aimed at femoral head preservation due to relatively poor results of hip arthroplasty treatment. Nonsurgical methods include pharmacologic agents and electrical stimulation. At least three of these factors are potential candidates as therapeutic modalities: cytokines, such as interleukins, tumour necrosis factors, and signalling molecules such as fibroblast growth factors, platelet derived growth factors, insulin-like growth factors, and transforming growth factor betas, bone morphogenetic proteins and angiogenic factors $[1,35]$.

Cytokines are redundant secreted proteins with growth, differentiation and activation functions that regulate immune responses and immune response cell function as well as trafficking. The cytokine produced in response to an immune insult determines whether an immune response will be produced and whether this response will be humoral, cytotoxic, cell-mediated or allergic. A cascade of responses to cytokines can be seen in an immune response, as well as cytokines synergising for an optimal immune function. Cytokines could have a completely different function depending on the cellular source, target and of course the specific state of the immune response [4].

Several molecular pathways regulate the balance between osteoclasts and osteoblasts and determine the rate of bone remodeling. Certain cytokines such as IL$1, \mathrm{TNF}-\mathrm{a}$ and other proinflammatory cytokines stimulate osteoclasts differentiation and activation [36]. Also it is known that TNF-a acts on osteoblasts or bone marrow cells to synthesize and release cytokines whose role is directly associated with osteoclasts proliferation and maturation [9].

In this study we tried to evaluate the contribution of specific gene polymorphisms of several cytokines in osteonecrosis, a disease where osteoclasts-osteoblasts balance is crucial for bone remodeling. Therefore, we examined samples from patients with osteonecrosis and normal samples for the polymorphisms within the genes of IL- $1 \alpha$, IL-1R, IL-1RA, IL-4R $\alpha$, IL-1 $\beta$, IL-12, $\gamma$ IFN, TGF- $\beta$, TNF-a, IL-2, IL-4, IL-6 and IL- 10 .

\section{Materials and methods}

\subsection{Study subjects}

Five hundred and fifty subjects of Caucasian origin (Greece and Cyprus) were selected. Peripheral blood samples from 112 patients diagnosed with osteonecrosis at the stages II-IV (ARCO) and 438 of healthy donors between 20 and 50 years old were collected in the Department of Orthopaedic Surgery of a University Hospital. In relation to osteonecrosis etiology, 76 patients received steroids for some period of time and 5 had renal transplantation. Also, 4 had sickle cell anaemia, 2 were diagnosed with Systemic Lupus Erythematosus (SLE) and 5 other patients were alcoholic. In the remaining 20 patients no etiologic correlation was found and they were diagnosed as idiopathic cases. Healthy controls were derived from the same geographical area with no history of bone disease. The study was approved by the Scientific Committee of the University Hospital of Larissa (Greece) and is in accordance with the 1964 Declaration of Helsinki.

DNA from peripheral blood was extracted using the QIAmp DNA Mini Kit (Qiagen, Hilden, Germany). DNA quality and quantity was determined by electrophoresis in $1 \%$ agarose gel and absorbance spectrophotometry.

\subsection{Cytokine genotyping}

Polymorphisms were analyzed using the PCR-SSP method (Sequence Specific Primers) and the Protrans kit (Protrans HLA Cytokines 2, Roche Diagnostics, Mannheim, Germany). This specific kit uses PCR techniques with allele- and polymorphism- specific primers in the amplification reaction, recognizing 22 different polymorphisms in 13 cytokines. Each of the primer mixes contained as a control a primer pair that amplified either a part of the $\beta$-globin gene or a part of the C-reactive protein (CRP) gene. The $\beta$-globin control primers produce a 89 -bp fragment, while the primer pairs amplifying the CRP gene produce a 440-bp amplicon. The allele and genotype frequencies of the following cytokine genes were determined: IL-1a (T/C -889), 


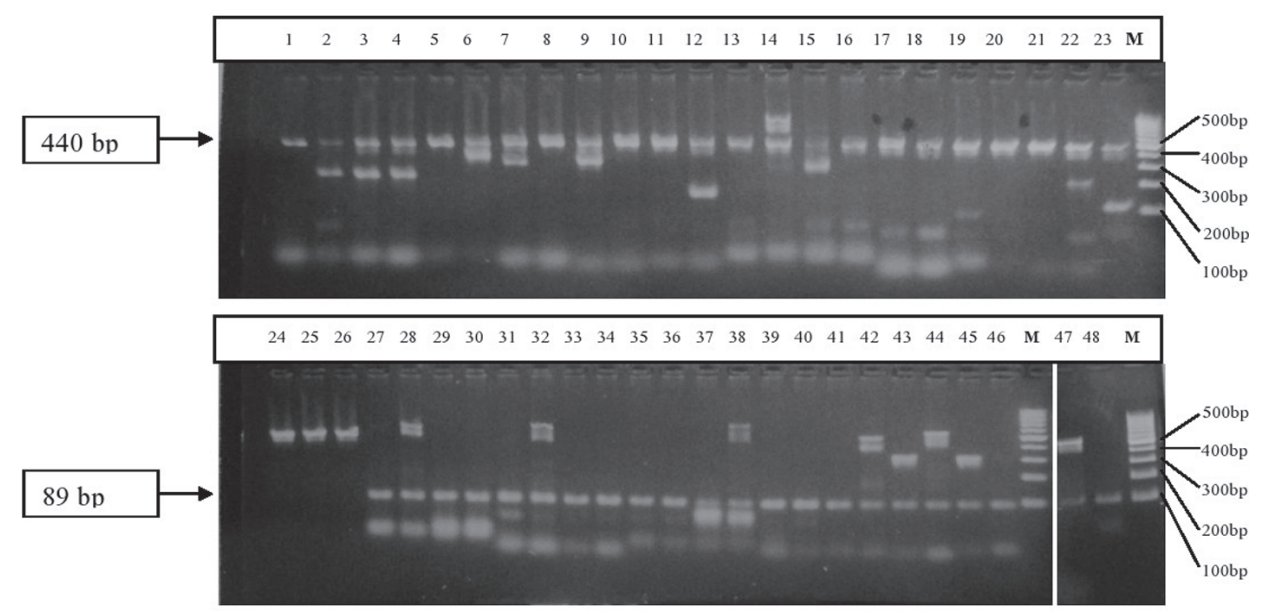

Fig. 1. Electrophoresis of a sample for 13 different cytokines carried 22 polymorphisms. The allele specific amplification products for IL-1 $\alpha$ (lanes 1-2), IL-1 $\beta$ (lanes 3-6), IL-1R (lanes 7-8), IL-1RA (lanes 9-10), IL-4R $\alpha$ (lanes 11-12), $\gamma$ IFN (lanes 15-16), TGF- $\beta$ (lanes 17-22) and TNF- $\alpha$ (23-26) are < 340 bp, for IL-12 (lanes 13-14) are > 800 bp and for IL-2 (lanes 27-30), IL-4 (lanes 31-38), IL-6 (lanes 39-42) and IL-10 (lanes 43-48) are $>300$ bp. M: marker 100bp.

IL-1 $\beta$ (C/T -511, T/C +3962), IL-1R (C/T pst11970), IL-1RA (T/C mspa111100), IL-4R $\alpha$ (G/A +1902), IL12 (C/A -1188), interferon (IFN)- $\gamma$ (A/T UTR 5644), transforming growth factor (TGF)- $\beta$ (C/T codon 10 , G/C codon 25), TNF-a (G/A -308, G/A -238), IL-2 (T/G -330, G/T +166), IL-4 (T/G -1098, T/C -590, T/C -33), IL-6 (G/C -174, G/A nt565), IL-10 (G/A -1082, C/T -819, C/A -592) (Fig. 1). All experiments were performed in triplicate.

\subsection{Statistical analysis}

Pearson $\chi^{2}$ or Fisher's exact test was applied to analyze the comparison of frequencies of discrete variables between patients and controls. The odds ratio (OR) with $95 \%$ confidence interval $(95 \% \mathrm{CI})$ were also calculated. All reported $\mathrm{p}$ values are two-tailed. Statistical significance was set at the $p<0.05$ and analyses were conducted using SPSS statistical software (version 17.0).

\section{Results}

Allele and genotype frequencies are summarized in Tables 1 and 2. Genotype distributions of the examined genes were in Hardy-Weinberg equilibrium $p<0.05$. The CT genotype in the IL- $1 \alpha$ at the -889 position was found in almost half of the patients $(51.8 \%)$ with prevalence of $\mathrm{T}$ allele being $34.8 \%$. In TGF- $\beta$ codon 25 , the $\mathrm{G}$ allele frequency was $91.1 \%$ in the patients group, while the CC genotype was found only in $1.8 \%$ in the same group $(p<0.05)$. At position -238 of the TNF-a gene promoter, $10.8 \%$ of the patients had the GA genotype and only $2.1 \%$ of the control group. The allele frequency of the A allele was in both groups very low (patients: $5.4 \%$, controls: $1.05 \%$ ) (Table 1). Haplotypes were created for all the polymorphic sites of all examined genes; the GG/GG haplotype for the positions $-308,-238$ of the TNF $\alpha$ gene promoter was more frequent in both groups, whereas the GG/GA haplotype was more frequent in patients group $(p<$ $0.05)$. At the -1082 position of the IL- 10 gene the GG genotype was significantly higher in the control group $(p<0.05)$. Moreover, the $\mathrm{GCC} / \mathrm{GCC}$ haplotype for $-1082,-819$ and -592 positions of IL-10 gene was more prevalent in the control group than in the patient group $(p<0.05)$ (Table 2$)$.

\section{Discussion}

Osteonecrosis is a disease of unknown pathogenesis that usually progresses to hip joint destruction necessitating total hip arthroplasty. The pathology involves ischemic events followed by death of bone and marrow elements [27,28]. Considerable effort using in vitro and in vivo models has been directed toward understanding the effect of cytokines on osteoblasts and osteoclasts and their ultimate effect on bone resorption and formation, since these two types of cells are responsible for bone renewal. It is now apparent that the activities 
Table 1

Genotype sequences of cytokine genes in ON patients and healthy group

\begin{tabular}{|c|c|c|c|c|c|}
\hline & Genotype & Patients & Controls & $\mathrm{P}$-value & OR $(95 \%$ CI $)$ \\
\hline \multirow{3}{*}{ IL-1 $1 \alpha$} & $\mathrm{CC}$ & $44(39.3 \%)$ & $211(48.2 \%)$ & 0.09 & \\
\hline & $\mathrm{CT}$ & $58(51.8 \%)$ & $174(39.7 \%)$ & 0.02 & $1.62(1.07-2.47)$ \\
\hline & TT & $10(8.9 \%)$ & $53(12.1 \%)$ & 0.34 & \\
\hline \multirow{3}{*}{ IL-1 $\beta$} & $\mathrm{CC}$ & $46(41.1 \%)$ & $197(45 \%)$ & 0.45 & \\
\hline & CT & $49(43.7 \%)$ & $186(42.4 \%)$ & 0.80 & \\
\hline & TT & $17(15.2 \%)$ & $55(12.6 \%)$ & 0.46 & \\
\hline \multirow[t]{3}{*}{ IL- $1 \beta$} & $\mathrm{CC}$ & $50(44.7 \%)$ & $233(53.2 \%)$ & 0.10 & \\
\hline & TC & $53(47.3 \%)$ & $183(41.8 \%)$ & 0.29 & \\
\hline & TT & $9(8 \%)$ & $22(5 \%)$ & 0.22 & \\
\hline \multirow{3}{*}{ IL-1R } & $\mathrm{CC}$ & $54(48.2 \%)$ & $191(43.6 \%)$ & 0.38 & \\
\hline & CT & $49(43.8 \%)$ & $192(43.8 \%)$ & 0.98 & \\
\hline & TT & $9(8 \%)$ & $55(12.6 \%)$ & 0.18 & \\
\hline \multirow[t]{3}{*}{ IL-1RA } & TT & $55(49.1 \%)$ & $211(48.2 \%)$ & 0.86 & \\
\hline & $\mathrm{TC}$ & $49(43.7 \%)$ & $186(42.5 \%)$ & 0.80 & \\
\hline & $\mathrm{CC}$ & $8(7.2 \%)$ & $41(9.3 \%)$ & 0.46 & \\
\hline \multirow{3}{*}{ IL-4Ra } & AA & $82(73.2 \%)$ & $340(77.6 \%)$ & 0.32 & \\
\hline & $\mathrm{GA}$ & $27(24.1 \%)$ & 87 (19.9\%) & 0.32 & \\
\hline & GG & $3(2.7 \%)$ & $11(2.5 \%)$ & 0.92 & \\
\hline \multirow[t]{3}{*}{ IL-12 } & AA & $69(61.6 \%)$ & $248(56.6 \%)$ & 0.34 & \\
\hline & $\mathrm{CA}$ & $36(32.1 \%)$ & $162(37 \%)$ & 0.34 & \\
\hline & $\mathrm{CC}$ & $7(6.3 \%)$ & $28(6.4 \%)$ & 0.95 & \\
\hline \multirow{3}{*}{$\gamma \mathrm{INF}$} & AA & $27(24.1 \%)$ & $116(26.5 \%)$ & 0.60 & \\
\hline & AT & $58(51.8 \%)$ & $219(50 \%)$ & 0.73 & \\
\hline & TT & $27(24.1 \%)$ & $103(23.5 \%)$ & 0.89 & \\
\hline \multirow[t]{3}{*}{ TGF- $\beta$ (codon 10$)$} & $\mathrm{CC}$ & $41(36.6 \%)$ & $139(31.7 \%)$ & 0.32 & \\
\hline & $\mathrm{CT}$ & $44(39.3 \%)$ & $200(45.7 \%)$ & 0.22 & \\
\hline & $\mathrm{TT}$ & $27(24.1 \%)$ & $99(22.6 \%)$ & 0.73 & \\
\hline \multirow{3}{*}{ TGF- $\beta$ (codon 25$)$} & GG & $94(84 \%)$ & $352(80.3 \%)$ & 0.39 & \\
\hline & GC & $16(14.2 \%)$ & $49(11.2 \%)$ & 0.36 & \\
\hline & $\mathrm{CC}$ & $2(1.8 \%)$ & $37(8.5 \%)$ & 0.02 & $0.19(0.04-0.83)$ \\
\hline \multirow{3}{*}{ TNF-a (-308) } & GG & $94(84 \%)$ & $369(84.3 \%)$ & 0.93 & \\
\hline & GA & $17(15.2 \%)$ & $58(13.2 \%)$ & 0.59 & \\
\hline & AA & $1(0.8 \%)$ & $11(2.5 \%)$ & 0.31 & \\
\hline \multirow[t]{3}{*}{ TNF-a (-238) } & GG & $100(89.2 \%)$ & $429(97.9 \%)$ & 0.04 & \\
\hline & GA & $12(10.8 \%)$ & $9(2.1 \%)$ & 0.00 & $0.17(0.07-0.42)$ \\
\hline & AA & $0(0 \%)$ & $0(0 \%)$ & 0.49 & \\
\hline \multirow{3}{*}{ IL-2 (-330) } & TT & $45(40.2 \%)$ & $168(38.4)$ & 0.72 & \\
\hline & TG & $44(39.3 \%)$ & $202(46.1 \%)$ & 0.19 & \\
\hline & GG & $23(20.5 \%)$ & $68(15.5 \%)$ & 0.20 & \\
\hline IL-2 (+166) & GG & $62(55.4 \%)$ & $235(53.6 \%)$ & 0.74 & \\
\hline & GT & $39(34.8 \%)$ & $165(37.7 \%)$ & 0.57 & \\
\hline & TT & $11(9.8 \%)$ & $38(8.7 \%)$ & 0.70 & \\
\hline IL-4 (-1098) & TT & $92(82.1 \%)$ & $360(82.2 \%)$ & 0.99 & \\
\hline & TG & $18(16.1 \%)$ & $64(14.6 \%)$ & 0.69 & \\
\hline & GG & $2(1.8 \%)$ & $14(3.2 \%)$ & 0.43 & \\
\hline IL-4 (-590) & TT & $6(5.4 \%)$ & $17(3.9 \%)$ & 0.48 & \\
\hline & $\mathrm{TC}$ & $22(19.6 \%)$ & $114(26 \%)$ & 0.16 & \\
\hline & $\mathrm{CC}$ & $84(75 \%)$ & $307(70.1 \%)$ & 0.30 & \\
\hline IL-4 (-33) & $\mathrm{TT}$ & $16(14.3 \%)$ & $98(22.4 \%)$ & 0.06 & \\
\hline & $\mathrm{TC}$ & $11(9.8 \%)$ & $24(5.5 \%)$ & 0.09 & \\
\hline & $\mathrm{CC}$ & $85(75.9 \%)$ & $316(72.1 \%)$ & 0.42 & \\
\hline IL-6 (-174) & GG & $73(65.2 \%)$ & $248(56.6 \%)$ & 0.10 & \\
\hline & GC & $35(31.2 \%)$ & $169(38.6 \%)$ & 0.15 & \\
\hline & $\mathrm{CC}$ & $4(3.6 \%)$ & $21(4.8 \%)$ & 0.58 & \\
\hline IL-6 (nt565) & GG & $74(66.1 \%)$ & $245(56 \%)$ & 0.05 & \\
\hline & GA & $34(30.3 \%)$ & $153(34.9 \%)$ & 0.36 & \\
\hline & AA & $4(3.6 \%)$ & $40(9.1 \%)$ & 0.06 & \\
\hline IL-10 (-1082) & GG & $8(7.2 \%)$ & $71(16.2 \%)$ & 0.01 & $0.39(0.18-0.85)$ \\
\hline & GA & $64(57.1 \%)$ & $220(50.2 \%)$ & 0.19 & \\
\hline & AA & $40(35.7 \%)$ & $147(33.6 \%)$ & 0.66 & \\
\hline IL-10 (-819) & $\mathrm{CC}$ & $64(57.1 \%)$ & $250(57 \%)$ & 0.99 & \\
\hline & $\mathrm{CT}$ & $39(34.8 \%)$ & $167(38.2 \%)$ & 0.51 & \\
\hline & TT & $9(8.1 \%)$ & $21(4.8 \%)$ & 0.18 & \\
\hline IL-10 (-592) & $\mathrm{CC}$ & $64(57.1 \%)$ & $250(57 \%)$ & 0.99 & \\
\hline & CA & $39(34.8 \%)$ & $167(38.2 \%)$ & 0.51 & \\
\hline & AA & $9(8.1 \%)$ & $21(4.8 \%)$ & 0.18 & \\
\hline
\end{tabular}

OR: Odds Ratio, CI: Confidence Interval. 
Table 2

Haplotype frequencies in ON patients and controls

\begin{tabular}{|c|c|c|c|c|c|c|}
\hline Cytokine & Position & Genotype & Patients & Controls & P-value & OR $(95 \% \mathrm{CI})$ \\
\hline \multirow[t]{4}{*}{$\mathrm{TNFa}$} & $(-308-238 /-308-238)$ & GG/GG & $82(73.2 \%)$ & $360(82.2 \%)$ & 0.03 & $0.59(0.36-0.96)$ \\
\hline & & GG/AG & $17(15.2 \%)$ & $58(13.2 \%)$ & 0.59 & \\
\hline & & GG/GA & $12(10.8 \%)$ & $9(2.1 \%)$ & 0.00 & $5.72(2.34-13.94)$ \\
\hline & & $\mathrm{AG} / \mathrm{AG}$ & $1(0.8 \%)$ & $11(2.5 \%)$ & 0.31 & \\
\hline \multirow[t]{6}{*}{ IL-10 } & $(-1082-819 /-1082-819)$ & $\mathrm{GC} / \mathrm{AC}$ & $43(38.3 \%)$ & $110(25.1 \%)$ & 0.00 & $1.85(1.19-2.87)$ \\
\hline & & GC/AT & $21(18.7 \%)$ & $110(25.1 \%)$ & 0.15 & \\
\hline & & $\mathrm{GC} / \mathrm{GC}$ & $8(7.2 \%)$ & $71(16.2 \%)$ & 0.01 & $0.39(0.18-0.85)$ \\
\hline & & AC/AT & $18(16.1 \%)$ & $57(13.1 \%)$ & 0.40 & \\
\hline & & $\mathrm{AC} / \mathrm{AC}$ & $13(11.6 \%)$ & $69(15.7 \%)$ & 0.27 & \\
\hline & & AT/AT & $9(8.1 \%)$ & $21(4.8 \%)$ & 0.18 & \\
\hline \multirow[t]{6}{*}{ IL-10 } & $(-1082-592 /-1082-592)$ & GC/AC & $43(38.3 \%)$ & $110(25.1 \%)$ & 0.00 & 1.85 (1.19-2.87) \\
\hline & & GC/AA & $21(18.7 \%)$ & $110(25.1 \%)$ & 0.15 & \\
\hline & & GC/GC & $8(7.2 \%)$ & $71(16.2 \%)$ & 0.01 & $0.39(0.18-0.85)$ \\
\hline & & AC/AA & $18(16.1 \%)$ & $57(13.1 \%)$ & 0.40 & \\
\hline & & $\mathrm{AC} / \mathrm{AC}$ & $13(11.6 \%)$ & $69(15.7 \%)$ & 0.27 & \\
\hline & & AA/AA & $9(8.1 \%)$ & $21(4.8 \%)$ & 0.18 & \\
\hline \multirow[t]{6}{*}{ IL-10 } & $(-1082-819-592 /$ & $\mathrm{GCC} / \mathrm{ACC}$ & $43(38.3 \%)$ & $110(25.1 \%)$ & 0.00 & $1.85(1.19-2.87)$ \\
\hline & $-1082-819-592)$ & GCC/ATA & $21(18.7 \%)$ & $110(25.1 \%)$ & 0.15 & \\
\hline & & ACC/ATA & $18(16.1 \%)$ & $57(13.1 \%)$ & 0.40 & \\
\hline & & $\mathrm{ACC} / \mathrm{ACC}$ & $13(11.6 \%)$ & $69(15.7 \%)$ & 0.27 & \\
\hline & & ATA/ATA & $9(8.1 \%)$ & $21(4.8 \%)$ & 0.18 & \\
\hline & & GCC/GCC & $8(7.2 \%)$ & $71(16.2 \%)$ & 0.01 & $0.39(0.18-0.85)$ \\
\hline
\end{tabular}

OR: Odds Ratio, CI: Confidence Interval.

of these two bone cell types are interrelated. Osteoclastic activity, and therefore resorption, appears to be modulated by cytokines released by osteoblasts. Polymorphisms in cytokine genes may result in interindividual variation in transcriptional regulation, and thus in differential cytokine production. It has been widely hypothesized that genetic variants of cytokines could have phenotypic relevance and influence an individual's internal microenvironment [21,22,37,39].

The frequency of the studied cytokine polymorphisms in our subjects, which were Caucasians with a Greek and Cypriot origin, was similar to those referred by Costeas et al. in Greek Cypriot people, except for those frequencies concerning the codons 10 and 25 of TGF- $\beta$ [8]. In more details, we showed that certain genotypes of the IL- $1 \alpha$, TGF- $\beta$, IL-10 and TNF-a genes could be related in the pathogenesis of a complicated disease, such as osteonecrosis. This finding could be useful in the prognosis and treatment of people at high risk for osteonecrosis, such as corticosteroid users.

Interleukin (IL)-1a is primarily a proinflammatory cytokine by its ability to stimulate the expression of genes associated with inflammation and immunity. Single nucleotide polymorphisms (SNPs) of the IL-1 $\alpha$ gene were reported to be associated with susceptibility to inflammatory diseases. More specifically, the SNP $\mathrm{C} / \mathrm{T}$ (rs1800587) at -889nt in the 5'-flanking region of IL-1 $\alpha$ gene has been associated with susceptibility to the inflammatory diseases, including periodontitis [18], juvenile idiopathic arthritis [23], psoriatic arthritis [33], Alzheimer's disease [32], preeclam- psia [13], and systemic lupus erythematosus [30]; however, this SNP could predict the response of the treatment for rheumatoid arthritis [6] and the human immunodeficiency virus infection [31]. In our study, the CT genotype in the polymorphic site -889 was significantly higher in our patients group than the control group. Since IL$1 \alpha$ is known to stimulate bone resorption via osteoclasts [17] and the T allele increases the protein level, thus it can be assumed that the CT heterozygotes carried higher protein levels resulting in an imbalance of osteoblasts/osteoclasts function.

TGF- $\beta$ is a multifunctional cytokine that regulates proliferation and differentiation of a wide spectrum of cells both in vivo and in vitro. TGF- $\beta$ influences cell growth, differentiation, apoptosis, cell migration, immune cell function and extracellular matrix production. It has been found that TGF- $\beta$ production varies from person to person and is partly dependent on the different TGF- $\beta$ gene polymorphisms. TGF- $\beta$ pathway was described to modulate the development of several disease groups, including cancer, atherosclerosis, autoimmune and also fibrotic disease [2,5]. Our results indicate a higher percentage of homozygosity of the polymorphic $\mathrm{C}$ allele in the codon 25 of the TGF- $\beta$ gene in the control group, while the $\mathrm{G} \rightarrow \mathrm{C}$ alteration in codon 25 (rs1800471) is associated with lower pro- 
duction of TGF- $\beta$. Therefore, $\mathrm{CC}$ homozygotes from the normal subjects will have lower TGF- $\beta$ production which could result in BMPs induction and be beneficial in bone regeneration, as it is known that TGF$\beta$ generally is considered to antagonize BMP-induced osteoblast differentiation [10].

Another anti-inflammatory cytokine, IL-10, is capable of inhibiting the synthesis of other pro-inflammatory cytokines such as IL-2, IL-3 and TNFa [24,42]. Our results showed that the haplotype GCC for the polymorphic sites $-1082,-819$ and -592 of IL-10 (rs 1800896, rs1800871 and rs1800872, respectively) gene was significantly associated with the control group. This haplotype is been responsible for a high capacity of IL-10 production which is in accordance with our findings. Also, the GC/GC genotypes for the IL-10 (-1082/-819) and IL-10 (-1082/-592) sites, appeared more frequent in the healthy donors. This specific genotype is associated with elevated levels of IL-10 and having in mind the inhibition role of IL-10 on other cytokines, we could hypothesize that especially the control group could benefit from this IL-10 excess, since this molecule has a restrictive role on other cytokines and their role.

A potent inflammatory cytokine, TNF-a, is released by macrophages in systemic inflammatory responses, regulating the inflammatory reaction and the immune response through promoting other cytokines expression. It is suggested that TNF-a acts on osteoblasts or bone marrow stromal cells to synthesize and release cytokines, such as IL-3, IL-6, IL-11 and IL-12 whose role is directly associated with the osteoclasts proliferation and maturation [9]. In fact, TNF-a acts as a skeletal catabolic agent that stimulates osteoclastogenesis while simultaneously inhibiting osteoblasts function [29]. TNF-a and RANKL are abundant in sites of inflammatory bone erosion and because these cytokines are potent osteoclastogenic factors and have overlapping signaling pathways, it is believed that under pro-inflammatory conditions RANKL and TNF-a might synergistically orchestrate enhanced osteoclastogenesis via cooperative mechanisms [43]. Our results demonstrate significant linkage of the genotype GA in TNF-a -238 polymorphic site in patients group. Moreover, the GG/GA haplotype at the -308 and -238 positions of TNF-a gene was higher in the patients group than the controls. The $\mathrm{G} \rightarrow \mathrm{A}$ alteration at the -238 (rs361525) site leads to an increased expression of the gene. Thus, it could be assumed that this augmentation in the patients group contributes in osteoclasts proliferation and loss of stability between osteoblasts and osteoclasts balance.

In conclusion, considerable effort using in vitro and in vivo models has been directed toward understanding the effect of cytokines on osteoblasts and osteoclasts and their ultimate effect on bone resorption and formation. It is now apparent that the activities of these two bone cell types are interrelated and their balance determines the rate of bone remodeling. Polymorphisms in the genes of cytokines can affect this balance. The presence of one of the above mentioned polymorphisms or the simultaneous carriage of more than one may further increase the risk for osteonecrosis, especially in patients receiving corticosteroids. The application of cytokines in the prognosis and therapy of osteonecrosis shows promise, although clinical studies on efficacy and safety are needed.

\section{References}

[1] Aldridge JM 3rd., Urbaniak JR. Avascular necrosis of the femoral head: etiology, pathophysiology, classification, and current treatment guidelines. Am J Orthop. 2004; 33:327-332.

[2] Amirzargar M, Yavangi M, Basiri A, Moghadam SH, Khosravi F, Solgi G, Gholiaf M, Khoshkho F, Dadaras F, Mahmmodi M, Ansaripour B, Amirzargar A, Nikbin B. Genetic Association of Interleukin-4, Interleukin-10, and Transforming Growth Factor Gene Polymorphism With Allograft Function in Renal Transplant Patients. Transplant Proc. 2007; 39:954-957.

[3] Assouline-Dayan Y, Chang C, Greenspan A, Shoenfeld Y, and Gershwin ME. Pathogenesis and natural history of osteonecrosis. Seminars in Arthritis and Rheumatism. 2002; 32:94-124.

[4] Borish LC, Steinke JW 2. Cytokines and chemokines. J Allergy Clin Immunol. 2003; 111(2 Suppl):S460-475.

[5] Brazova J, Sismova K, Vavrova V, Bartosova J, Macek Jr. M, Lauschmand H, Sediva A. Polymorphisms of TGF-beta1 in cystic fibrosis patients. Clin Immunol. 2006; 121:350-357.

[6] Camp NJ, Cox A, di Giovine FS, McCabe D, Rich W, Duff GW. Evidence of a pharmacogenomic response to interleukin1 receptor antagonist in rheumatoid arthritis. Genes Immun. 2005; 6:467-471.

[7] Celik A, Tekis D, Saglam F, Tunali S, Kabakci N, Ozaksoy D, Manisali M, Ozcan MA, Meral M, Gülay H, Camsari T. Association of corticosteroids and factor V, prothrombin, and MTHFR gene mutations with avascular osteonecrosis in renal allograft recipients. Transplant Proc. 2006; 38:512-516.

[8] Costeas PA, Koumas L, Koumouli A, Kyriakou-Giantsiou A, Papaloizou A. Cytokine polymorphism frequencies in the Greek Cypriot population. Eur J Immunogenet. 2003; 30:341343.

[9] Dai CY, Chuang WL, Lee LP, Chen SC, Hou NJ, Lin ZY, Hsieh MY, Hsieh MY, Wang LY, Chang WY, Yu ML. Associations of tumor necrosis factor alpha promoter polymorphisms at position -308 and -238 with clinical characteristics of chronic hepatitis C. J Viral Hep. 2006; 13:770-774.

[10] De Gorter DJ, van Dinther M, Korchynskyi O, Ten Dijke P. Biphasic effects of transforming growth factor $\beta$ on bone morphogenetic protein-induced osteoblast differentiation. J Bone Miner Res. 2011; 26:1178-1187.

[11] Etienne G, Mont MA, Ragland PS. The diagnosis and treatment of nontraumatic osteoecrosis of the femoral head. Instr Course Lect. 2004; 53:67-85. 
[12] Hadjigeorgiou G, Dardiotis E, Dardioti M, Karantanas A, Dimitroulias A, Malizos K. Genetic association studies in osteonecrosis of the femoral head. Skelet Radiol. 2008; 37:1-7.

[13] Haggerty CL, Ferrell RE, Hubel CA, Markovic N, Harger $\mathrm{G}$, Ness RB. Association between allelic variants in cytokine genes and preeclampsia. Am J Obstet Gyneco. 2005; 193:209215 .

[14] Inoue S, Horii M, Asano T, Fujioka M, Ogura T, Shibatani M, Kim WC, Nakagawa M, Tanaka T, Hirota Y, Kubo T. Risk factors for nontraumatic osteonecrosis of the femoral head after renal transplantation. J Orthop Sci. 2003; 8:751-756.

[15] Jones JP Jr. Coagulopathies and osteonecrosis. Acta Orthopaedica Belgica. 1999; 65(Suppl 1):5-8.

[16] Kim YH, Kim JS, Park JW, Joo JH. Total hip replacement with a short metaphyseal-fitting anatomical cementless femoral component in patients aged 70 years or older. J Bone Joint Surg Br. 2011; 93:587-92.

[17] Knudsen S, Harsløf T, Husted LB, Carstens M, Stenkjaer L, Langdahl BL. The effect of interleukin-1alpha polymorphisms on bone mineral density and the risk of vertebral fractures. Calcif Tissue Int. 2007; 80:21-30.

[18] Laine ML, Farré MA, González G, van Dijk LJ, Ham AJ, Winkel EG, Crusius JB, Vandenbroucke JP, van Winkelhoff AJ, Peña AS. Polymorphisms of the interleukin-1 gene family, oral microbial pathogens, and smoking in adult periodontitis. J Dent Res. 2001; 80:1695-1699.

[19] LaPorte DM, Mont MA, Mohan V, Jones LC, Hungerford DS. Multifocal osteonecrosis. J Rheumatol. 1998; 25:1968-1974.

[20] Lieberman JR, Berry DJ, Mont MA, Aaron RK, Callaghan JJ, Rajadhyaksha AD, Urbaniak JR. Osteonecrosis of the hip: management in the 21st century. Instr Course Lect. 2003; 52:337-355.

[21] Loughrey BV, Maxwell AP, Fogarty DG, Middleton D, Harron JC, Patterson CC, Darke C, Savage DA. An interleukin 1B allele, which correlates with a high secretor phenotype, is associated with diabetic nephropathy. Cytokine. 1998; 10:984988.

[22] Lv L, Kerzic P, Lin G, Schnatter AR, Bao L, Yang Y, Zou $\mathrm{H}, \mathrm{Fu} \mathrm{H}$, Ye X, Gross SA, Armstrong TW, Irons RD. The TNF-238A polymorphism is associated with susceptibility to persistent bone marrow dysplasia following chronic exposure to benzene. Leuk Res. 2007; 31:1479-1485.

[23] McDowell TL, Symons JA, Ploski R, Førre O, Duff GW. A genetic association between juvenile rheumatoid arthritis and a novel interleukin-1 alpha polymorphism. Arthritis Rheum. 1995; 38:221-228.

[24] Miyazoe S, Hamasaki K, Nakata K, Kajiya Y, Kitajima K, Nakao K, Daikoku M, Yatsuhashi H, Koga M, Yano M, Eguchi K. Influence of Interleukin-10 Gene Promoter Polymorphisms on Disease Progression in Patients Chronically Infected With Hepatitis B Virus. Am J Gastrenterol. 2002; 97: 2086-2092.

[25] Mont MA, Hungerford DS. Non-traumatic avascular necrosis of the femoral head. J Bone Joint Surg Am. 1995; 77:459-474.

[26] Mont MA, Glueck CJ, Pacheco IH, Wang P, Hungerford DS, Petri M. Risk factors for osteonecrosis in systemic lupus erythematosus. J Rheumatol. 1997; 24:654-662.

[27] Mont M, Jones L, Einhorn T, Hungerford DS, Reddi AH. Osteonecrosis of the femoral head: potential with growth and differentiation factors. Clin Orthop. 1998; 355S:S314-S335.
[28] Mont MA, Jones LC, Hungerford DS. Nontraumatic Osteonecrosis of the Femoral Head: Ten Years Later. J Bone Joint Surg Am. 2006; 88:1117-1132.

[29] Nanes MS. Tumor necrosis factor- $\alpha$ : molecular and cellular mechanisms in skeletal pathology. Gene. 2003; 321:-1-15.

[30] Parks CG, Pandey JP, Dooley MA, Treadwell EL, St Clair EW, Gilkeson GS, Feghali-Bostwick CA, Cooper GS. Genetic polymorphisms in tumor necrosis factor (TNF)-alpha and TNF-beta in a population-based study of systemic lupus erythematosus: associations and interaction with the interleukin1alpha-889 C/T polymorphism. Hum Immunol. 2004; 65:622631.

[31] Price P, James I, Fernandez S, French MA. Alleles of the gene encoding IL-1alpha may predict control of plasma viraemia in HIV-1 patients on highly active antiretroviral therapy. AIDS. 2004; 18:1495-1501.

[32] Rainero I, Bo M, Ferrero M, Valfrè W, Vaula G, Pinessi L. Association between the interleukin-1alpha gene and Alzheimer's disease: A meta-analysis. Neurobiol Aging. 2004; 25:1293-1298.

[33] Ravindran JS, Owen P, Lagan A, Lewis J, Korendowych E, Welsh K, McHugh N. Interleukin 1alpha, interleukin 1beta and interleukin 1 receptor gene polymorphisms in psoriatic arthritis. Rheumatology (Oxford). 2004; 43:22-26.

[34] Soucacos PN, Beris AE, Malizos K, Koropilias A, Zalavras $\mathrm{H}$, Dailiana Z. Treatment of avascular necrosis of the femoral head with vascularized fibular transplant. Clin Orthop Relat Res. 2001; 386:120-130.

[35] Soucacos PN, Urbaniak JR. Osteonecrosis of the human skeleton. Orthop Clin North Am. 2004; 35(3):xiii-xv.

[36] Strand V, Kavanaugh AF. The role of interleukin-1 in bone resorption in rheumatoid arthritis. Rheumatology (Oxford). 2004; 43: iii10-iii16.

[37] Suarez A, Castro P, Alonso R, Mozo L, Gutierrez C. Interindividual variations in constitutive interleukin-10 messenger RNA and protein levels and their association with genetic polymorphisms. Transplantation. 2003; 75:711-717.

[38] Urbaniak JR, Jones JP. Osteonecrosis: Etiology, diagnosis and treatment. American Orthopaedic Association, 1997, pp. 385390.

[39] Yuan B, Liu Z. Treatment of osteonecrosis of the femoral head: Combination of operation and multiple cellular mediators. Med Hypotheses. 2007; 68:502-505.

[40] Zalavras C, Dailiana Z, Elisaf M, Bairaktari E, Vlachogiannopoulos P, Katsaraki A, Malizos KN. Potential aetiological factors concerning the development of osteonecrosis of the femoral head. Eur J Clin Invest. 2000; 30:215-221.

[41] Zalavras GC, Malizos K, Dokou E, Vartholomatos G. The $677 \mathrm{C} \rightarrow \mathrm{T}$ mutation of the methylene-tetrahydrofolate reductase gene in the pathogenesis of osteonecrosis of the femoral head. Hematologica. 2002; 87:111-112.

[42] Zhang X, Hei P, Deng L, Lin J. Interleukin-10 gene promoter polymorphisms and their protein production in peritoneal fluid in patients with Endometriosis. Mol Hum Reprod. 2007; 13:135-140.

[43] Zhang YH, Heulsmann A, Tondravi MM, Mukherjee A, Abu-Amer Y. Tumor necrosis factor-alpha (TNF) stimulates RANKL-induced osteoclastogenesis via coupling of TNF type 1 receptor and RANK signaling pathways. J Biol Chem. 2001; 276(1): 563-8. 


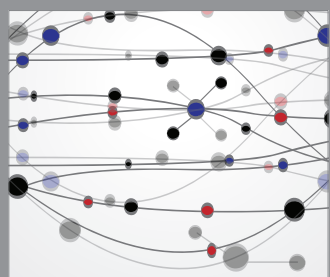

The Scientific World Journal
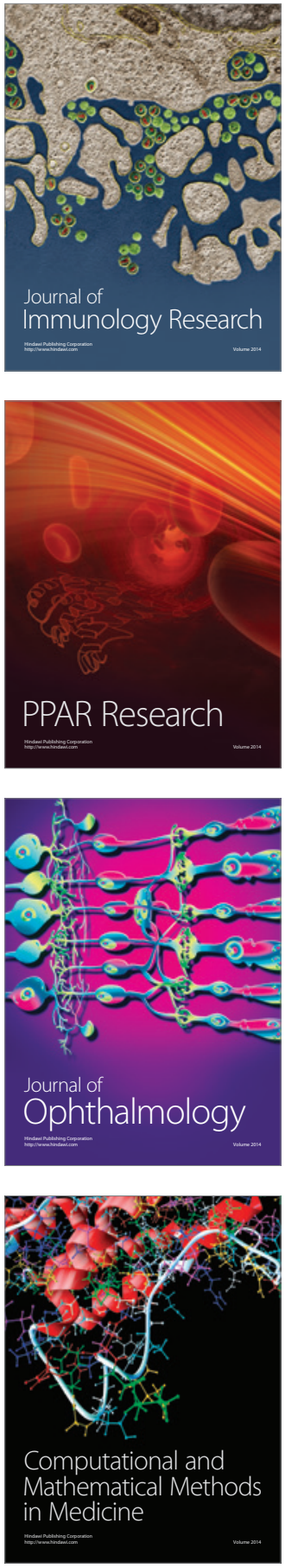

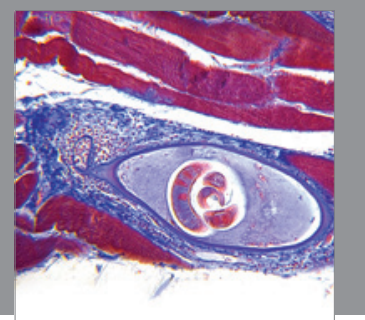

Gastroenterology

Research and Practice
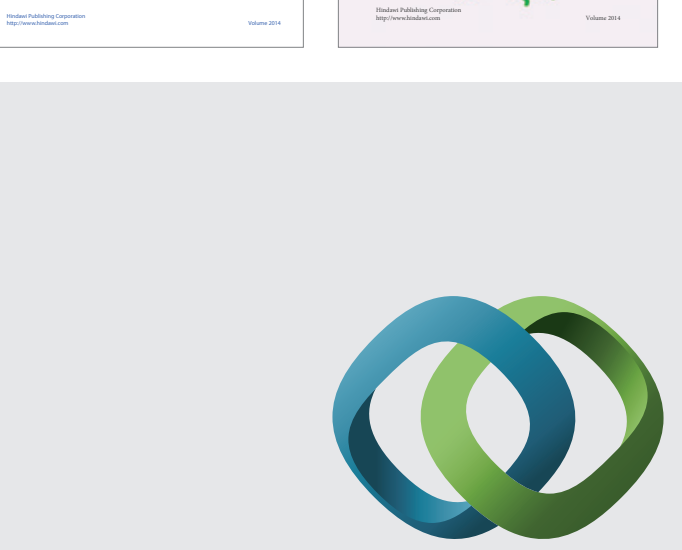

\section{Hindawi}

Submit your manuscripts at

http://www.hindawi.com
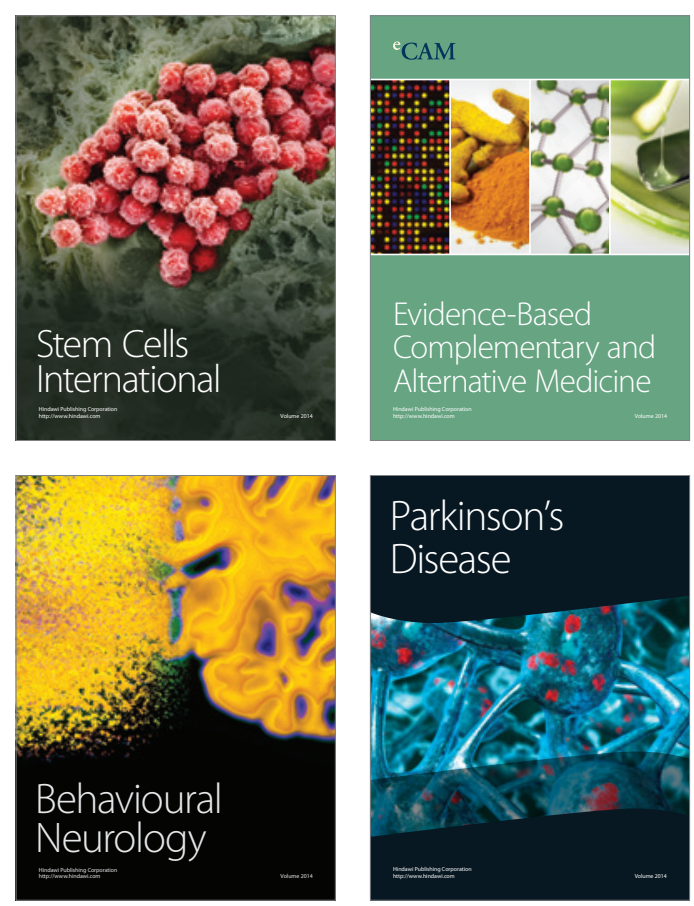

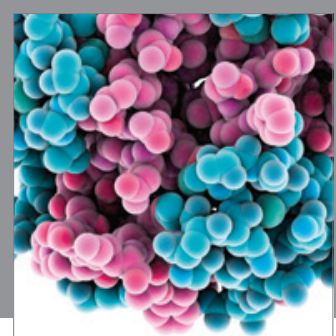

Journal of
Diabetes Research

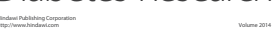

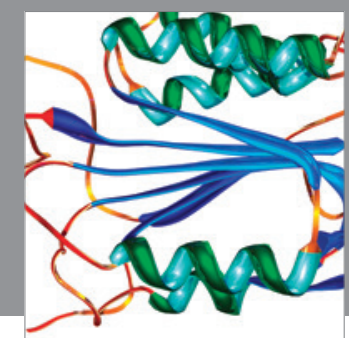

Disease Markers
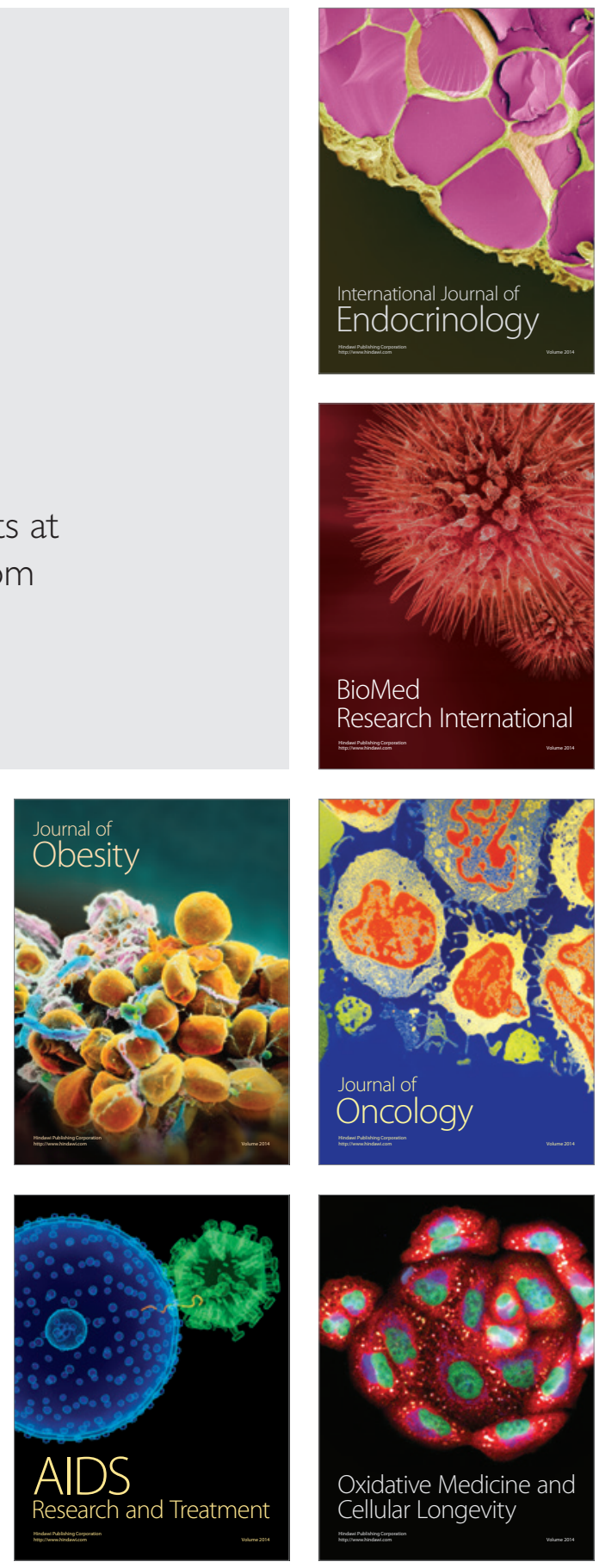